\title{
Occupational UV exposure in French outdoor workers
}

Running title: Occupational UV exposure in French outdoor workers

Mathieu BONIOL, PhD ${ }^{1,2, *}$, Alice KOECHLIN, Ing ${ }^{1,2}$, Magali BONIOL, $\mathrm{MSc}^{2}$,
Faustine VALENTINI, M.A. ${ }^{2}$, Marie-Christine CHIGNOL, MSc ${ }^{3}$, Jean-Francois

DORE, $\mathrm{PhD}^{3}$, Jean-Luc BULLIARD, $\mathrm{PhD}^{4}$, Antoine MILON, MSc ${ }^{5}$, David VERNEZ, $\mathrm{PhD}^{5}$.

1. University of Strathclyde Institute of Global Public Health, Lyon, France

2. International Prevention Research Institute, iPRI, Lyon, France

3. Centre de Recherche en Cancérologie de Lyon, UMR Inserm U1052 - CNRS U5286, Lyon, France

4. Cancer Epidemiology Unit, Institute of Social and Preventive Medicine, Lausanne University Hospital, Lausanne, Switzerland

5. Institute of Work and Health (IST), University of Lausanne and Geneva, Lausanne, Switzerland.

* Corresponding author:

Prof. Mathieu Boniol

International Prevention Research Institute, 95 cours Lafayette, 69006 Lyon, France

Tel: +33472171185

Fax: +33472171190

Email: mathieu.boniol@i-pri.org

\section{Conflict of interest and source of funding}

This work was supported by a research grant from ANSES N.EST-2011/1/075 (principal investigator: David Vernez). We declare no conflict of interest.

Manuscript (excluding abstract and tables): word count:2084, text pages : 9

Abstract: word count:134

Number of figures: 0

Number of tables: 3 


\begin{abstract}
(word count: 134)
Objectives: Occupational UV exposure was evaluated in a population-based sample in
\end{abstract} France.

Methods: A random survey was conducted in 2012 in individuals aged 25 to 69 years. Median daily standard erythemal UV dose (SED) was estimated from exposure time, place and matched to satellite UV records.

Results: 889 individuals were exposed to solar UV with highest doses observed among: gardeners (1.19 SED), construction workers (1.13 SED), agricultural workers (0.95 SED), and culture/art/social sciences workers (0.92 SED). Information and communication technology, industry and transport workers were highly exposed (above 0.70 SED). Significant factors associated with high occupational UV exposure were gender $(\mathrm{p}<0.0001)$, phototype $(\mathrm{p}=0.0003)$ and taking lunch outdoors $(\mathrm{p}<0.0001)$.

Conclusion: This study identified expected occupations with high UV exposure but also unexpected occupations with high exposures. This could serve as a basis for future prevention.

\title{
Introduction
}

The International Agency for Research on Cancer (IARC) has classified ultraviolet (UV) radiation as group \#1 carcinogen in 2009 because of its role in the development of skin cancer.[1] UV radiation has also an important established role in the occurrence of eye diseases (cataract, ocular melanoma, etc.), skin ageing, immunosuppression and vitamin D synthesis.

The population among which UV exposure can be expected to be the highest is outdoor workers as this group is already at particularly increased risk of basal cell carcinoma [2] and squamous cell carcinoma.[3]

The European Agency for Safety and Health at Work reported that 14.5 million workers in the European Union are exposed to solar UV at least $75 \%$ of their working time. [4] This estimation, based on 15 countries, established from expert opinion and extrapolated from prevalence data in Finland, is very likely underestimating the number of outdoor workers in the whole of Europe. 
Most studies on occupational UV exposure focussed on specific jobs. These studies included on site evaluation with dosimeters and have already provided good evaluation of UV exposure in these populations such as in farmers [5-6], construction workers [7-8] or vineyard workers.[9] However, they did not provide an overall picture of jobs exposed to UV.

We identified one study carried out according to the CAREX methodology which is based on expert's assessment of exposure.[10] While this methodology is perfectly adapted to known carcinogens for which exposures are industry-dependent and uncommon, it might not be adequate for UV radiation.

A survey was conducted in France to assess, in the general population, occupational exposure to solar UV radiation. The objective of this study was to produce an overview of outdoor occupations and sectors from the perspective of employees, and to quantify UV exposure for identified categories of jobs.

\section{Methods}

A population-based survey was performed in France in May-June 2012 on a sample of workers aged 25 to 69 years and exposed to UV radiation at work, both artificial UV and solar radiation. Individuals were selected by random digit dialling and were interviewed by trained personnel through computer-assisted telephonic interviews (CATI). The survey was conducted by the company ENOV Research.

A quota by major French regions was applied to obtain a representative sample of the distribution of population in mainland France, including Corsica. Individuals were considered as exposed to UV radiation if they reported cumulating one year of occupational UV exposure during the past five years and for more than one day per week for solar radiation. This enabled to remove potential student part-time jobs and to keep individuals with seasonal activity.

For each individual, the current place of residence was registered using city name, department and post code. These places were geo-localised based on post codes from the French National Institute of Statistics and Economic Studies.[11] For 174 cities for which the automatic matching was not possible due to incomplete post codes, longitude and latitude data were extracted manually based on city name and department.[12] These 
longitude and latitude data were matched to the nearest point in the EuroSun database.[13] Average daily UV radiation data for the 2003-2007 period were extracted from this database.

The average distance between longitude/latitude and EuroSun coordinates was 2.9 kilometres. UV data in EuroSun were only available for UVA and UVB. To express these values as erythemal UV in $\mathrm{kJ} / \mathrm{m}^{2}$ or standard erythemal dose (SED), erythemal UV (UVe) data were extracted from Tropospheric Emission Monitoring Internet Service for six sites in France (Briançon, Bordeaux, Haute Provence, Lyon, Paris, and Villeneuve d'Ascq) from $01 / 01 / 2003$ to $31 / 12 / 2007$.[14] These UVe data were compared to UVB from EuroSun. The average difference in coordinates between matched nearest point in EuroSun database and in TEMIS dataset was 2.8 kilometres and did not exceed 4.7 kilometres. In a linear model, a ratio UVe/UVB was computed as a function of latitude which was applied to all UVB data from EuroSun.

The interview recorded information on occupational exposure during the past five years with description of sector, job description as well as time of the day when job started and ended and total daily exposure duration. These data were available by season if the job involved seasonal changes in outdoor exposure or for the entire year. From the declared starting hour and ending hour of activity, the area under the curve of the hourly UV radiation in clear sky condition was computed from a reference curve. This reference of UV radiation throughout the day was extracted from HelioClim3 database. Data were extracted for clear sky for year 2005 at latitude 45 degrees North and longitude 2 degrees East for five days per season that were averaged.[15]

This computation resulted in the proportion of UV radiation corresponding to the declared hours, to which was multiplied the proportion of time outdoor that individuals declared per day. The result of this computation was the proportion of the daily UV radiation per individual that was further applied to the daily average UV radiation extracted from Eurosun data. This UV radiation corresponds therefore to the average ambient UV radiation that workers could have experienced.

Each occupation reported during the last five years was recorded as open-ended questions on activity and sector. Answers to these questions were used to classify individuals by sector of activities based on the International Standard Industrial Classification of All 
Economic Activities (ISIC), $4^{\text {th }}$ revision.[16] Jobs were also classified according to the 2008 revision of the International Standard Classification of Occupations (ISCO-08).[17] Two authors conducted independently classification of sector and jobs, and disagreements were reviewed with a third author. Jobs were further grouped according to main categories of jobs and type of activities (for example grouping armed force workers and protective services workers), all groupings are detailed in appendix 1.

To compare UV radiation between categories of outdoor workers (gender, age groups, phototype, frequency of lunch outdoor), the Kruskal-Wallis test was used. Analyses were conducted using SAS statistical software version 9.2 (SAS Institute Inc). Two-sided pvalues of less than $5 \%$ were considered statistically significant.

\section{Results}

A total of 998 workers exposed to UV radiation were interviewed. Ninety-two individuals only exposed to artificial UV and 17 individuals with no reported duration of exposure were excluded. Finally, 889 individuals reporting exposure to solar UV radiation and for which an average daily UV radiation exposure could be estimated were included in the present study. Out of 889 outdoor workers, the majority (63\%) were men. In addition, men accumulated an average higher exposure to UV radiation than women (Table 1). This male excess was job-dependent with higher proportion of men observed for construction workers (93\%) and no men among child care workers. The median age of the population of outdoor workers was 41 years (interquartile range 33 to 50), with no major difference for all jobs except farmers who were notably older (median age 52, interquartile range 41.5 to 57 ). Exposure to UV radiation did not differ by age.

In our study population, most individuals had an educational level of "Baccalaureat" (ALevel) or below (58\%). They were also often of less sensitive phototype: skin type III or IV represented $71 \%$ of the workers. Phototype IV subjects were the most exposed to UV radiation.

A minority of participants (34\% often or always) had to take lunch outdoors because of their occupation. These workers were more exposed to UV radiation than others.

The five more frequent job categories with outdoor sun exposure were gardeners, landscapers, construction workers, agricultural workers, culture, art, social workers, 
industry workers, and a group labelled "others" which included various unqualified works as leaflet distributors, dustmen, lunchtime supervisors, etc (Table 2). Farmers, landscapers/gardeners and construction workers were exposed to important daily UV radiation. Even if they represented a minority, culture, art and social science workers were also exposed to significant UV radiations with a median of $0.92 \mathrm{~kJ} / \mathrm{m}^{2}$ per day.

The groups of "office administrative employees" and "managers and senior executives" were classified as such based on the job description (for example director), but their activity sector generally belonged to activities described for other jobs. For example, "office administrative employees" could be technical assistants working for a train company, or "managers and senior executives" a director of a company of real estate agents. Median UVe exposures by main codes of ISCO classification of jobs and of ISIC classification of sectors were also presented in appendices 2 and 3, respectively.

The maximum of daily average across all seasons of UV exposure was computed for each individual (Table 3). The ranking of jobs substantially changed; some seasonal occupations had extreme exposures in summer, for example "culture, art and social workers".

\section{Discussion}

The present study enabled the identification of jobs associated with important average daily UV exposure in France. The most exposed jobs were landscapers/gardeners, construction workers, farmers, and culture, art and social science workers.

Because of the definition of occupational exposure, which required at least one year during the past 5 years, and because the place of residence was used as a proxy to place of work, our study did not cover younger age groups. Based on a different design, further studies would be helpful to assess the exposure in outdoor workers less than 25 years of age.

A potential limitation to this study is the reconstruction of UV exposure which is based on declaration of the schedule in the past years of employment, and an approximation based on satellite data and modelling. Under-estimation of exposure is likely to append for some occupations due to local condition at a worksite. For example, construction workers could sometimes be exposed to a greater amount of UV because of reflexion 
of concrete and glass which would increase UV exposure. Hence, these estimations are not to be considered as a standard, and onsite studies with personal dosimeters should remain the gold standard for evaluating individual exposure to UV. Of note, our estimations are in the order of magnitude that could be expected for France when compared to previous work using personal dosimeters in Europe.[7,18-19] These estimations are naturally much lower than those measured in Australian population.[2021]

The main advantage of our method is that it requires data on time, duration and place of exposure and UV data. UV data can be easily extracted from satellite data. Doses can be computed quickly for a large number of workers exposed in various areas. By comparison, on-site measurements require considerable time and logistics. The limitation of this method is the lack of validation so far. A validation study with on-site measurements and personal dosimeters in a sample of selected workers is required.

Our estimation provides a very good indication of ranking of occupations by exposure to solar radiation. Such ranking is unlikely to be biased by uncertainties on the measurements of UV radiation.

Like exposure to any carcinogen such as ionising radiations, occupational exposure to UV will likely require an active individual surveillance. This surveillance would enable the recording of quantitative assessment of exposure with information on the number of workers, preventive measures, type of protection, nature and degree of exposure.[22]

Several photoprotection methods already exist to decrease UV exposure.[23] Attention should be given to protection other than sunscreens [24] which have proven to be inappropriate for occupational activities because of major drawbacks such as high price, insufficient water resistance and sticky appearance.[25]

The International Commission on Non-Ionizing Radiation Protection (ICNIRP) published documentation on potential methods for UV protection. These guidelines have been entirely adopted by WHO. Even though these guidelines do not help defining the level of exposure of workers, they provide a series of methods that could be adopted by workers for photoprotection. [26] 
Further studies are ongoing to identify the best protection methods for each outdoor activity based on simulation of distribution of UV on anatomical site according to body posture.[27-28]

There is no specific legal constraint in France defining occupational exposure limits to solar UV radiation to which we could compare our results. However, ICNIRP's recommends a maximum of about 1.0 to 1.3 SED [26] which would be regularly and largely exceeded in several workers in the present study.

Our study helps to better characterize outdoors workers and jobs exposed to highest levels of UV radiation. Photoprotection methods do exist to strongly diminish damages from UV radiation. We encourage employers of outdoor workers, in particular in fields identified in this study, to take actions to reduce exposure of their employees to fulfil their legal obligation of safety at work.

\section{References}

1 El Ghissassi F, Baan R, Straif K et al. WHO International Agency for Research on Cancer Monograph Working Group. A review of human carcinogens--part D: radiation. Lancet Oncol 2009;10:751-2.

2 Bauer A, Diepgen TL, Schmitt J. Is occupational solar ultraviolet irradiation a relevant risk factor for basal cell carcinoma? A systematic review and metaanalysis of the epidemiological literature. Br J Dermatol 2011;165:612-25.

3 Schmitt J, Seidler A, Diepgen TL et al. Occupational ultraviolet light exposure increases the risk for the development of cutaneous squamous cell carcinoma: a systematic review and meta-analysis. Br J Dermatol 2011;164:291-307.

4 European Agency for Safety and Health at Work. Outlook 1 - New and emerging risks in occupational safety and health, 2009.

5 Airey DK, Wong JC, Fleming RA et al. An estimate of the total UV-B exposure for outdoor workers during a south-east Queensland summer. Health Phys 1997;72:544-9.

6 Schmalwieser AW, Cabaj A, Schauberger G, et al. Facial solar UV exposure of Austrian farmers during occupation. Photochem Photobiol 2010;86:1404-13. 
7 Serrano MA, Cañada J, Moreno JC; Members of the Valencia Solar Radiation Research Group. Solar UV exposure in construction workers in Valencia, Spain. $J$ Expo Sci Environ Epidemiol 2013;23:525-30.

8 Milon A, Sottas P-E, Bulliard J-L et al. Effective exposure to solar UV in building workers: influence of local and individual factors. J Expo Sci Environ Epidemiol 2007; 17:58-68

9 Siani AM, Casale GR, Sisto R, et al. Occupational exposures to solar ultraviolet radiation of vineyard workers in Tuscany (Italy). Photochem Photobiol 2011;87:925-34.

10 Peters CE, Nicol AM, Demers PA. Prevalence of exposure to solar ultraviolet radiation (UVR) on the job in Canada. Can J Public Health 2012;103:223-6.

11 INSEE, coordonnées GPS WGS84 (longitude, latitude) des villes françaises (http://dotclear.placeoweb.com/post/code-postal-insee-coordonees-gps-wgs84longitude-latitude-des-villes-en-france, last accessed 26 June 2012)

12 Find your GPS Coordinates (http://www.longitude-latitude-maps.com, last accessed 10 March 2014)

13 Eurosun Project website (www.eurosun-project.org, last accessed 10 March 2014)

14 TEMIS, UV station data based on satellite data (http://www.temis.nl/uvradiation/SCIA/stations_uv.html, last accessed 10 March 2014)

15 Solar Energy Services for Professionals (http://www.soda-is.com/eng/index.html, last accessed 10 March 2014).

16 United Nations Statistics Division. International Standard Industrial Classification of All Economic Activities $\quad$ (ISIC), Rev.4. (http://unstats.un.org/unsd/publication/seriesM/seriesm_4rev4e.pdf, last accessed 10 March 2014)

17 International Labour Organization. International Standard Classification of Occupations (ISCO-08) (http://www.ilo.org/wcmsp5/groups/public/---dgreports/---dcomm/--publ/documents/publication/wcms_172572.pdf, last accessed 10 March 2014) 
18 Thieden E, Collins SM, Philipsen PA et al. Ultraviolet exposure patterns of Irish and Danish gardeners during work and leisure. Br. J. Dermatol 2005;153:795801.

19 Thieden E, Philipsen PA, Heydenreich J et al. UV radiation exposure related to age, sex, occupation, and sun behavior based on time-stamped personal dosimeter readings. Arch Dermatol 2004;140:197-203.

20 Gies P, Watzl R, Javorniczky J et al. Measurement of the UVR exposures of expeditioners on antarctic resupply voyages. Photochem. Photobiol 2009;85:1485-90.

21 Vishvakarman D, Wong JC, Boreham BW. Annual occupational exposure to ultraviolet radiation in central Queensland. Health Phys 2001;81:536-44.

22 Journal Officiel de l'Union Européenne. Directive 2004/37/EC, Article 6: Informations de l'autorité compétente, and Annex II.2: Recommandations pratiques en vue de la surveillance médicale des travailleurs. (http://eurlex.europa.eu/LexUriServ/LexUriServ.do?uri=OJ:L:2004:229:0023:0034:fr:PDF, last accessed 10 March 2012)

23 Lautenschlager S, Wulf HC, Pittelkow MR. Photoprotection. Lancet 2007;370:528-37.

24 Boniol M, Autier P, Doré JF. Photoprotection. Lancet. 2007;370(9597):1481-2.

25 Maier H, Schmalwieser AW. Sunscreens and occupation: the Austrian experience. Photochem Photobiol Sci 2010;9:510-5.

26 International Commission on Non-Ionizing Radiation Protection. Protecting Workers from Ultraviolet Radiation Protection. ICNIRP 14/2007 (http://www.icnirp.de/documents/UVWorkers.pdf, last accessed 11 March 2014)

27 Vernez D, Milon A, Vuilleumier L et al. Anatomical exposure patterns of skin to sunlight: relative contributions of direct, diffuse and reflected ultraviolet radiation. Br J Dermatol 2012;167:383-90.

28 Vernez D, Milon A, Vuilleumier L et al. A general model to predict individual exposure to solar UV by using ambient irradiance data. J Expo Sci Environ Epidemiol Published Online First: 5 February 2014. doi: 10.1038/jes.2014.6 
Table 1. Description of the population of outdoor workers in France in 2012 and average daily erythemal UV dose in $\mathrm{kJ} / \mathrm{m}^{2}$.

\begin{tabular}{|c|c|c|c|c|c|c|c|}
\hline & & & Lower & & Upper & & \\
\hline & $\mathbf{N}$ & Minimum & Quartile & Median & Quartile & Maximum & p-value* \\
\hline$\overline{A g e}$ & & & & & & & 0.3378 \\
\hline $25-29$ & 117 & 0.02 & 0.45 & 0.78 & 1.17 & 1.77 & \\
\hline $30-34$ & 155 & 0.04 & 0.31 & 0.69 & 1.07 & 1.85 & \\
\hline $35-39$ & 118 & 0.04 & 0.41 & 0.74 & 1.14 & 1.64 & \\
\hline $40-44$ & 136 & 0.05 & 0.44 & 0.78 & 1.16 & 1.79 & \\
\hline $45-49$ & 125 & 0.00 & 0.42 & 0.72 & 1.14 & 1.81 & \\
\hline $50-54$ & 101 & 0.10 & 0.56 & 0.85 & 1.10 & 1.60 & \\
\hline $55-59$ & 67 & 0.03 & 0.41 & 0.75 & 1.06 & 1.56 & \\
\hline $60-64$ & 55 & 0.02 & 0.55 & 0.84 & 1.09 & 1.77 & \\
\hline $65-69$ & 15 & 0.41 & 0.66 & 1.09 & 1.25 & 1.8 & \\
\hline Sex & & & & & & & $<0.0001$ \\
\hline Men & 559 & 0.02 & 0.48 & 0.88 & 1.17 & 1.85 & \\
\hline Women & 330 & 0.00 & 0.31 & 0.62 & 1.00 & 1.77 & \\
\hline Phototype & & & & & & & 0.0003 \\
\hline । & 59 & 0.13 & 0.30 & 0.70 & 1.05 & 1.72 & \\
\hline II & 195 & 0.00 & 0.32 & 0.63 & 1.04 & 1.85 & \\
\hline III & 297 & 0.02 & 0.42 & 0.77 & 1.09 & 1.81 & \\
\hline IV & 338 & 0.02 & 0.50 & 0.89 & 1.19 & 1.79 & \\
\hline Lunch outdoor & & & & & & & $<0.0001$ \\
\hline Never & 240 & 0.00 & 0.40 & 0.75 & 1.07 & 1.77 & \\
\hline Sometimes & 343 & 0.02 & 0.32 & 0.64 & 1.06 & 1.85 & \\
\hline Often & 144 & 0.07 & 0.42 & 0.81 & 1.14 & 1.77 & \\
\hline Always & 162 & 0.12 & 0.69 & 1.04 & 1.27 & 1.81 & \\
\hline
\end{tabular}

* Kruskal-Wallis test 


\section{Table 2. List of group of jobs of outdoor workers in France in 2012 ranked by median daily erythemal UV dose (in $\mathrm{kJ} / \mathrm{m}^{2}$ ).}

\begin{tabular}{|c|c|c|c|c|c|c|}
\hline & \multirow{2}{*}{$\mathbf{N}$} & \multirow[b]{2}{*}{ Minimum } & Lower & \multicolumn{3}{|c|}{ Upper } \\
\hline & & & Quartile & Median & Quartile & Maximum \\
\hline Gardeners, landscapers & 23 & 0.14 & 0.82 & 1.19 & 1.32 & 1.47 \\
\hline Construction workers & 126 & 0.02 & 0.79 & 1.13 & 1.28 & 1.77 \\
\hline Others & 14 & 0.21 & 0.50 & 1.04 & 1.28 & 1.63 \\
\hline Agricultural workers & 108 & 0.07 & 0.70 & 0.95 & 1.14 & 1.81 \\
\hline Culture, art, social workers & 16 & 0.11 & 0.65 & 0.92 & 1.21 & 1.85 \\
\hline Industry workers & 36 & 0.10 & 0.45 & 0.79 & 1.13 & 1.57 \\
\hline $\begin{array}{l}\text { Information and communication } \\
\text { technology, telecommunication workers }\end{array}$ & 11 & 0.07 & 0.19 & 0.79 & 1.05 & 1.52 \\
\hline Transport workers and mail carriers & 97 & 0.10 & 0.56 & 0.77 & 1.06 & 1.72 \\
\hline Office administrative employees & 77 & 0.00 & 0.37 & 0.73 & 1.10 & 1.46 \\
\hline $\begin{array}{l}\text { Commercial sales workers and } \\
\text { business service agents }\end{array}$ & 29 & 0.16 & 0.51 & 0.69 & 1.00 & 1.75 \\
\hline Managers and senior executives & 19 & 0.14 & 0.32 & 0.63 & 1.12 & 1.55 \\
\hline $\begin{array}{l}\text { Protective services workers and armed } \\
\text { forces occupations }\end{array}$ & 60 & 0.11 & 0.41 & 0.62 & 0.97 & 1.57 \\
\hline $\begin{array}{l}\text { Engineers, researchers, life science } \\
\text { professionals }\end{array}$ & 55 & 0.02 & 0.31 & 0.61 & 1.03 & 1.77 \\
\hline $\begin{array}{l}\text { Health professionals and associates } \\
\text { and personal care workers }\end{array}$ & 35 & 0.05 & 0.28 & 0.60 & 1.01 & 1.54 \\
\hline Leisure and sport workers & 20 & 0.04 & 0.24 & 0.59 & 1.16 & 1.79 \\
\hline $\begin{array}{l}\text { Craft and related trades workers, } \\
\text { Shopkeepers }\end{array}$ & 42 & 0.06 & 0.36 & 0.54 & 0.91 & 1.60 \\
\hline Cleaners and personal service workers & 42 & 0.03 & 0.23 & 0.49 & 1.01 & 1.67 \\
\hline $\begin{array}{l}\text { Restaurant workers (restaurant } \\
\text { managers, waiters, fast food preparers) }\end{array}$ & 10 & 0.28 & 0.28 & 0.46 & 0.62 & 0.71 \\
\hline Teaching professionals & 51 & 0.04 & 0.14 & 0.35 & 0.68 & 1.56 \\
\hline Child care workers & 18 & 0.13 & 0.26 & 0.33 & 0.50 & 1.47 \\
\hline
\end{tabular}


Table 3. List of group of jobs of outdoor workers in France in 2012 ranked by the maximum seasonal ${ }^{*}$ average of daily erythemal UV dose (in $\mathbf{k J} / \mathrm{m}^{2}$ ).

\begin{tabular}{|c|c|c|c|c|c|c|}
\hline & \multirow[b]{2}{*}{$\mathbf{N}$} & \multirow[b]{2}{*}{ Minimum } & Lower & \multicolumn{3}{|c|}{ Upper } \\
\hline & & & Quartile & Median & Quartile & Maximum \\
\hline Gardeners, landscapers & 23 & 0.24 & 1.27 & 1.84 & 2.13 & 2.33 \\
\hline Construction workers & 126 & 0.06 & 1.32 & 1.76 & 1.95 & 2.67 \\
\hline Culture, art, social workers & 16 & 0.22 & 1.22 & 1.75 & 2.01 & 3.08 \\
\hline Others & 14 & 0.30 & 0.71 & 1.65 & 1.89 & 3.03 \\
\hline Agricultural workers & 108 & 0.12 & 1.28 & 1.56 & 1.98 & 3.15 \\
\hline Industry workers & 36 & 0.16 & 0.69 & 1.28 & 1.81 & 2.45 \\
\hline \multicolumn{7}{|l|}{ Information and communication } \\
\hline technology, telecommunication workers & 11 & 0.12 & 0.32 & 1.26 & 1.93 & 2.42 \\
\hline Transport workers and mail carriers & 97 & 0.16 & 0.93 & 1.19 & 1.65 & 2.74 \\
\hline Office administrative employees & 77 & 0.01 & 0.66 & 1.18 & 1.72 & 2.33 \\
\hline \multicolumn{7}{|l|}{ Health professionals and associates } \\
\hline and personal care workers & 35 & 0.14 & 0.52 & 1.15 & 1.66 & 2.79 \\
\hline Leisure and sport workers & 20 & 0.12 & 0.58 & 1.11 & 1.90 & 2.80 \\
\hline \multicolumn{7}{|l|}{ Commercial sales workers and } \\
\hline business service agents & 29 & 0.51 & 0.76 & 1.08 & 1.59 & 2.70 \\
\hline \multicolumn{7}{|l|}{ Protective services workers and armed } \\
\hline forces occupations & 60 & 0.18 & 0.69 & 1.03 & 1.59 & 2.55 \\
\hline Managers and senior executives & 19 & 0.22 & 0.59 & 1.01 & 2.04 & 2.32 \\
\hline \multicolumn{7}{|l|}{ Engineers, researchers, life science } \\
\hline professionals & 55 & 0.06 & 0.57 & 1.01 & 1.64 & 2.65 \\
\hline \multicolumn{7}{|l|}{ Craft and related trades workers, } \\
\hline Shopkeepers & 42 & 0.09 & 0.61 & 0.94 & 1.57 & 2.49 \\
\hline Cleaners and personal service workers & 42 & 0.05 & 0.40 & 0.84 & 1.77 & 2.50 \\
\hline \multicolumn{7}{|l|}{ Restaurant workers (restaurant } \\
\hline managers, waiters, fast food preparers) & 10 & 0.44 & 0.54 & 0.67 & 1.08 & 1.62 \\
\hline Child care workers & 18 & 0.27 & 0.46 & 0.65 & 1.05 & 2.21 \\
\hline Teaching professionals & 51 & 0.06 & 0.25 & 0.58 & 1.10 & 2.24 \\
\hline
\end{tabular}

${ }^{*}$ the maximum average was reached in summer for most workers, but for 6 individuals the maximum UV was found in Autumn and for 64 in Spring. 


\section{Statement on clinical significance of the present study}

This study provides a ranking of the most UV exposed occupations using standard classification for occupations and sectors (ISCO-08, ISIC4th). It confirms several occupations which were properly identified for their high exposure from empirical observations. This study presents some forgotten occupations which would require equal attention in future prevention. 
Copyright Transfer and Disclosure Form (one form per author)DV
Click here to download Copyright Transfer and Disclosure Form (one form per author): dvernez-240914-082930.w16639.pdf . Click her to down $\sqrt{2}$ 
Copyright Transfer and Disclosure Form (one form per author) MB
Click here to download Copyright Transfer and Disclosure Form (one form per author): copyrightTransfer_MB.pdf 
Copyright Transfer and Disclosure Form (one form per author) AK
Click here to download Copyright Transfer and Disclosure Form (one form per author): copyrightTransfer_AK.pdf

df

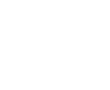
(2) . .

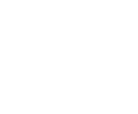
$-$ -

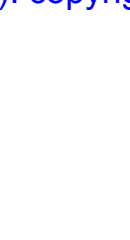

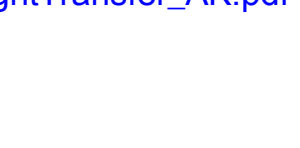

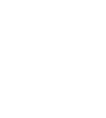

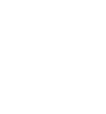

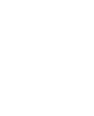
$\sqrt{2}$

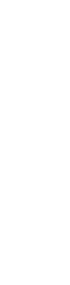


Copyright Transfer and Disclosure Form (one form per author)MagB
Click here to download Copyright Transfer and Disclosure Form (one form per author): copyrightTransfer_MagB.pdf 
Copyright Transfer and Disclosure Form (one form per author)FV
Click here to download Copyright Transfer and Disclosure Form (one form per author): copyrightTransfer_article JOEM_valentini.pdf

.

.

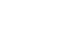

.

.

.

.

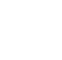

.

.

.

.

.

.

.

.

.

.

.

.

.

.

.

.

.

.

.

.

.

.

.

.

. 
Copyright Transfer and Disclosure Form (one form per author)MCC
Click here to download Copyright Transfer and Disclosure Form (one form per author): copyrightTransfer_chignol.pdf 
Copyright Transfer and Disclosure Form (one form per author)JFD
Click here to download Copyright Transfer and Disclosure Form (one form per author): renamed_2af21.pdf 
Copyright Transfer and Disclosure Form (one form per author)JLB
Click here to download Copyright Transfer and Disclosure Form (one form per author): JOEMcopyrightTransferJLB.pdf

Copyright Transfer and Disclosure Form (one form per author)JLB
Click here to download Copyright Transfer and Disclosure Form (one form per author): JOEMcopyrightTransferJLB.pdf 
Copyright Transfer and Disclosure Form (one form per author)AM
Click here to download Copyright Transfer and Disclosure Form (o Click here to download Copyright Transfer and Disclosure Form (one form per author): copyrightTransfer_AM.pdf 
Supplemental Digital Content
Click here to download Supple

Click here to download Supplemental Digital Content: REV_Supplementary File1.docx

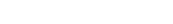

Click here to download Supplemental Digital Content: REV_Supplementary File1.docx
\end{abstract} (1) (3)

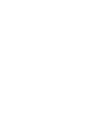

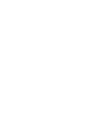

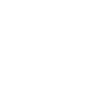
(1) (1) (1) (1) . . 
Supplemental Digital Content
Click here to download Supple

Click here to download Supplemental Digital Content: REV_Supplementary File2.docx

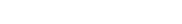

Click here to download Supplemental Digital Content: REV_Supplementary File2.docx
\end{abstract}

(1)

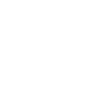

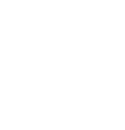

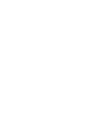
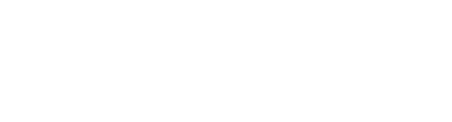
Supplemental Digital Content
Click here to download Supple

Click here to download Supplemental Digital Content: REV_Supplementary File3.docx

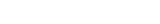
Click here to download Supplemental Digital Content:REV_Supplementary File3.docx

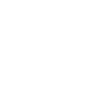
r . . . . . .

.

